\title{
Vouchering of Forensically Important Fly Specimens by Nondestructive DNA Extraction
}

\author{
Seong Yoon Kim, ${ }^{1}$ Seong Hwan Park, ${ }^{2}$ Huguo Piao, ${ }^{3}$ \\ Ukhee Chung, ${ }^{2}$ Kwang Soo Ko, ${ }^{2}$ and Juck-Joon Hwang ${ }^{2}$ \\ ${ }^{1}$ Division of Medical Entomology, Korea National Institute of Health, Korea Centers for Disease Control and Prevention, \\ Osong 363-700, Republic of Korea \\ ${ }^{2}$ Department of Legal Medicine, College of Medicine, Korea University, 126-1 Anam-dong 5-ga, Seongbuk-gu, \\ Seoul 136-705, Republic of Korea \\ ${ }^{3}$ Beijing Scales Forensic Center, 100 Chaoyangru, Chaoyang-qu, Beijing 100025, China
}

Correspondence should be addressed to Seong Hwan Park; kuforen@gmail.com

Received 12 November 2012; Accepted 28 November 2012

Academic Editors: J. D. Andrade Filho, A. I. Kehr, and J. Klimaszewski

Copyright (C) 2013 Seong Yoon Kim et al. This is an open access article distributed under the Creative Commons Attribution License, which permits unrestricted use, distribution, and reproduction in any medium, provided the original work is properly cited.

\begin{abstract}
DNA extraction frequently requires destruction of whole samples. However, when the sample is very rare or has taxonomic importance, nondestructive DNA extraction is required for preservation of voucher specimens. In the case of arthropod specimens, minor anatomical structures such as a single leg or a single wing are often sacrificed instead of the whole body for DNA extraction. In an attempt to save the entire anatomical structure of specimens, several authors tried to brew the whole specimen in a lysis buffer and to extract DNA from the "soup." We applied this nondestructive DNA extraction technique to a forensically important blowfly species, Phaenicia sericata. With nondestructive DNA extraction, a satisfactory quantity and quality of DNA for PCR amplification was obtained with only minimal anatomical disruptions that do not alter the morphologic identification. This nondestructive method may be applicable to DNA extraction of rare samples as well as vouchering of regular fly samples.
\end{abstract}

\section{Introduction}

Most DNA extraction methods inevitably consume at least a small portion of biological specimens. Of course, minor damages to samples do not matter in many instances and many small insect samples are even totally grinded for DNA extraction [1-4]. However, because photographic records prior to sample destruction do not always preserve all the important morphologic features, saving voucher specimens is advisable for specimens with taxonomic importance. In the case of forensically important fly species, many authors have utilized small portions of the body such as legs, wings, thoracic muscle, and entire thorax [5-9]. However, preserving the entirety of the specimen is often preferred, and dissection of specific anatomical parts such as the thoracic muscle is often complex and time consuming. In 1995, Phillips and Simon tried to extract DNA from unimpaired arthropod specimens in the museum collection. However, Phillips and Simon made multiple punctures to the exoskeletons prior to the extraction and did not describe the detailed morphological disruptions after the extraction [10]. The idea to brew whole unimpaired samples in a lysis buffer and to extract DNA from the "soup" has emerged in the field of zoology. Rohland et al. extracted DNA from mammalian teeth without any destruction of the specimen by incubating the whole specimen in a digestion buffer [11]. Gilbert et al. and Rowley et al. applied Rohland's method to beetles and various insect specimens and tested not only the DNA yields and qualities but also degrees of damages to the exoskeletons $[12,13]$. Although Rowley et al. included a fly species Delphinia picta in their study, it is taxonomically distant from most forensically important fly species [13]. To our knowledge, there has been no study which applied the nondestructive DNA extraction technique to forensically important fly species. We tested a 
TABLE 1: List of primers.

\begin{tabular}{llc}
\hline Primer names & Primer sequences & PCR product sizes \\
\hline COI-F(tRNA cystein) & CCTTTAGAATTGCAGTCTAATGTCA & $1738 \mathrm{bp}$ \\
COI-R(COII) & CCTAAATTTGCTCATGTTGACA & $629 \mathrm{bp}$ with COI-R(COII) \\
COI-F(1001 22) & CTGCTACTTTATGAGCTTTAGG \\
ITS2-F & GAACTGCAGGACACATGAAC & $492 \mathrm{bp}$ \\
ITS2-R & CCTCCCCTCATTAATATGCT & \\
\hline
\end{tabular}

TABLE 2: DNA concentrations and yields.

\begin{tabular}{lccc}
\hline Sample number & DNA concentration $(\mathrm{ng} / \mu \mathrm{L})$ & $260 / 280$ ratio & Yield $(\mu \mathrm{g})$ \\
\hline 1 & 78.6 & 1.53 & 3.14 \\
2 & 41.7 & 1.71 & 1.67 \\
3 & 34.5 & 1.87 & 1.38 \\
4 & 167.4 & 1.78 & 6.70 \\
5 & 384.6 & 1.55 & 15.38 \\
\hline Average & 141.4 & 1.69 & 5.65 \\
\hline
\end{tabular}

nondestructive DNA extraction method for artificially reared Phaenicia sericata ( $P$. sericata) specimens and compared key morphological features before and after DNA extraction.

\section{Materials and Methods}

2.1. Fly Specimens. Five artificially reared individuals of $P$. sericata were collected from the cage. Collected flies were anesthetized with ethylacetate and then submerged in $70 \%$ ethyl alcohol solution. After overnight treatment at $-20^{\circ} \mathrm{C}$, submerged specimens were picked out and air-dried at room temperature. Dried specimens were observed and recorded as digital images under a dissecting microscope.

2.2. DNA Extraction. Fly specimens were totally submerged in $400 \mu \mathrm{L}$ volume of lysis buffer solution $(100 \mathrm{mM} \mathrm{NaCl}$, $10 \mathrm{mM}$ Tris, $5 \mathrm{mM}$ EDTA, $2 \%$ SDS, and $0.2 \mathrm{mg} / \mathrm{mL}$ proteinase $\mathrm{K})$ and incubated for 4 hours at $55^{\circ} \mathrm{C}$ without shaking. Although overnight incubation may guarantee a better DNA yield, as it did for Gilbert et al. [12], we adopted the incubation time from Rowley et al. [13], who included thin-cuticled taxa for their experiments. After incubation, fly samples were submerged in $100 \%$ ethyl alcohol for further storage. The incubated lysis buffer was processed by classic phenol/chloroform DNA extraction method [14]. Precipitated DNA was eluted in a $40 \mu \mathrm{L}$ volume of double-distilled $\mathrm{H}_{2} \mathrm{O}$. DNA concentration was measured by ultraviolet absorbance at $260 \mathrm{~nm}$.

2.3. Postextraction Photographs. After DNA extraction, fly specimens were removed from $100 \%$ ethyl alcohol and dried at room temperature. Postextraction photographs were taken in the same manner as the preextraction photographs.

2.4. Polymerase Chain Reaction (PCR). Primer pairs for cytochrome c oxidase subunit I (COI) gene and ribosomal internal transcribed spacer 2 (ITS2) were chosen for assessment of
PCR amplificability from mitochondrial and nuclear DNA, respectively. Primer sequences and PCR amplicon sizes are listed in Table 1 . For each $10 \mu \mathrm{L}$ reaction volume, $20 \mathrm{ng}$ of fly DNA, 25 nmole of $\mathrm{MgCl}_{2}, 2$ pmole of each dNTP, $2 \times 10^{-6}$ pmole of each primer, $0.2 \mathrm{U}$ of Amplitaq Gold DNA polymerase (Applied Biosystems, Foster City, CA), and $1.0 \mu \mathrm{L}$ of $10 \mathrm{x}$ PCR buffer were used. After 1 cycle at $95^{\circ} \mathrm{C}$ for $11 \mathrm{~min}$ of hot start enzyme activation, fly DNAs were amplified by 35 cycles at $95^{\circ} \mathrm{C}$ for $30 \mathrm{sec}, 55^{\circ} \mathrm{C}$ for $30 \mathrm{sec}$, $72^{\circ} \mathrm{C}$ for $90 \mathrm{sec}$, and $72^{\circ} \mathrm{C}$ for $15 \mathrm{~min}$ of final extension with GeneAmp 2720 or 9600 PCR Systems (Applied Biosystems, Foster City, CA). However, for the primer pair COI-F(tRNA Cystein) and COI-R(COII), PCR cycles and extension time were increased to 40 and $120 \mathrm{sec}$, respectively. Amplified DNA fragments were visualized with electrophoreses in 3\% agarose gels, which consist of 2\% Nusieve and 1\% Seakem (Cambrex, Charles City, IA).

\section{Results}

3.1. DNA Yields. DNA concentrations and yields are summarized in Table 2. The yield of sample number 5 is about eleven times larger than that of sample number 3. Even with minimal yield $(1.38 \mu \mathrm{g})$, a PCR amplification using $50 \mathrm{ng}$ of DNA template can be performed twenty-seven times. If each PCR covers a 500-base pair DNA fragment, twentyseven PCRs can cover 13,500 base pairs of DNA sequence. With the average yield $(5.65 \mu \mathrm{g})$, the same PCR amplification can be performed up to 113 times. Therefore, the amount of DNA extracted with the nondestructive DNA extraction was sufficient for full coverage of most molecular markers for species identification, such as COI and ITS2.

3.2. PCR Amplification. All five samples displayed visible DNA bands for all three primer pairs (Figure 1). However, band intensities were weak for the primer pair COI-F(tRNA Cystein) and COI-R(COII), for which the amplicon size 


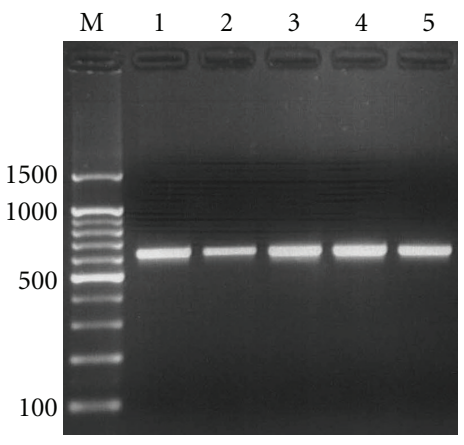

(a)

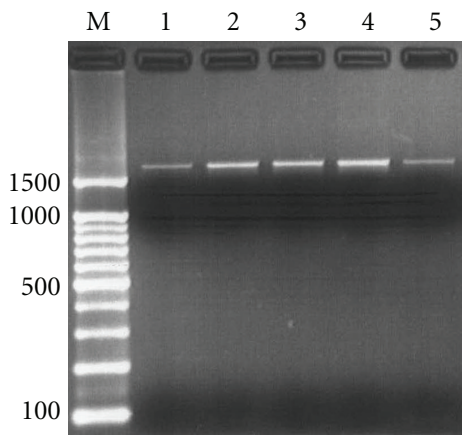

(b)

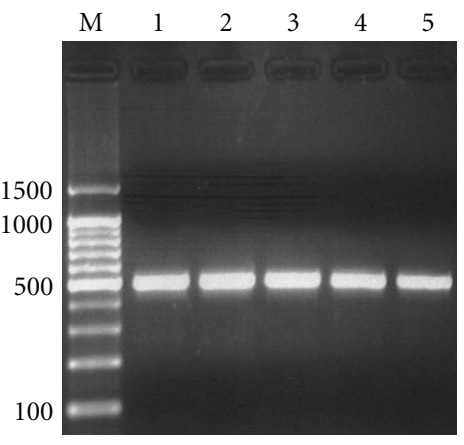

(c)

FIGURE 1: Electrophoresis results for 1738 and 629 base pair amplicons of COI genes (a and b, resp.) and 492 base pair amplicons of ITS2 region (c). "M" stands for "molecular size marker."

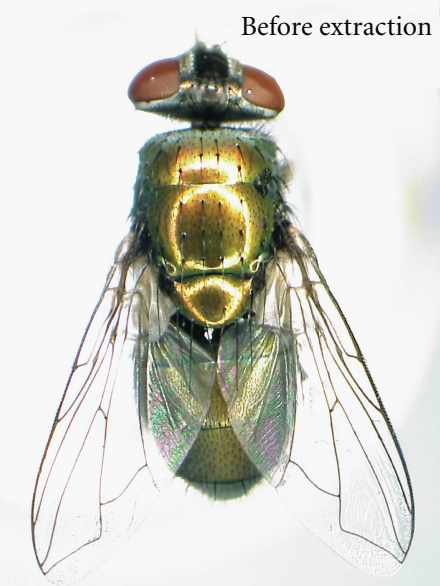

(a)

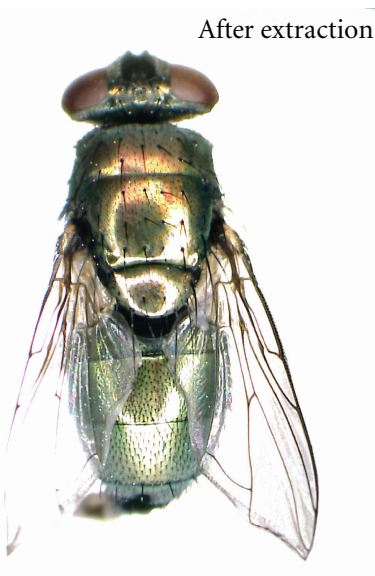

(b)

Figure 2: Comparing dorsal views of a fly sample before and after DNA extraction, the overall morphology is well preserved except for a slight dullness of metallic gloss and disarray of dorsal setae.

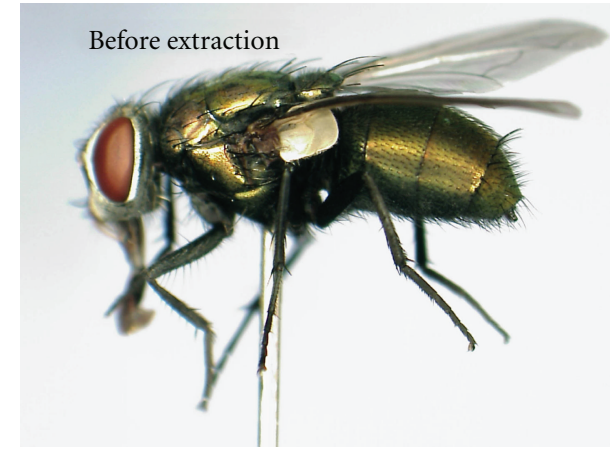

(a)

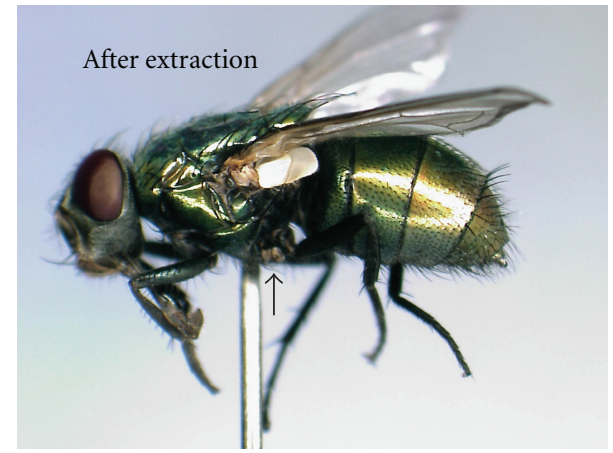

(b)

FIGURE 3: Lateral view of a fly sample of which the left mid leg has been lost (arrow) after DNA extraction. 
TABLE 3: Key morphological features after DNA extraction.

\begin{tabular}{|c|c|c|c|}
\hline \multirow{2}{*}{ Anatomical regions } & \multirow{2}{*}{ Important characteristics } & \multicolumn{2}{|c|}{ Number of flies } \\
\hline & & No changes & Minor disruption \\
\hline \multicolumn{4}{|l|}{ Head } \\
\hline Occipital setae & 3 to 8 pairs of bristles & 5 & 0 \\
\hline Segments of antennae & & 5 & 0 \\
\hline Arista & long plumose & 5 & 0 \\
\hline Palpus & & 5 & 0 \\
\hline \multicolumn{4}{|l|}{ Thorax } \\
\hline Acrostichal bristles & $2+3$ pairs of bristles & 5 & 0 \\
\hline Dorsocentral bristles & $3+3$ pairs of bristles & 5 & 0 \\
\hline Notopleural bristles & 2 bristles & 5 & 0 \\
\hline Postalar declivity & 6 to 8 pairs of fine hairs & 5 & 0 \\
\hline Propleuron & numerous hairs & 5 & 0 \\
\hline Suprasquamal ridge & numerous black hairs & 5 & 0 \\
\hline Hypopleural bristles & & 5 & 0 \\
\hline Basicosta & orange color & 5 & 0 \\
\hline Integrity of wings & pattern of veins & 0 & 5 \\
\hline Forelegs & 1 pair & 5 & 0 \\
\hline Mid legs & 1 pair & 3 & 2 \\
\hline Hind legs & 1 pair & 5 & 0 \\
\hline
\end{tabular}

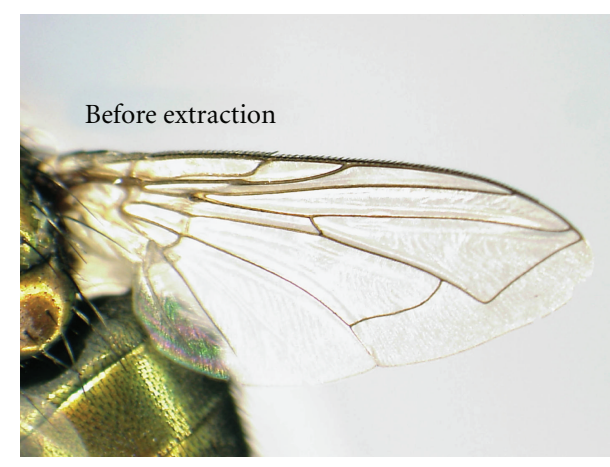

(a)

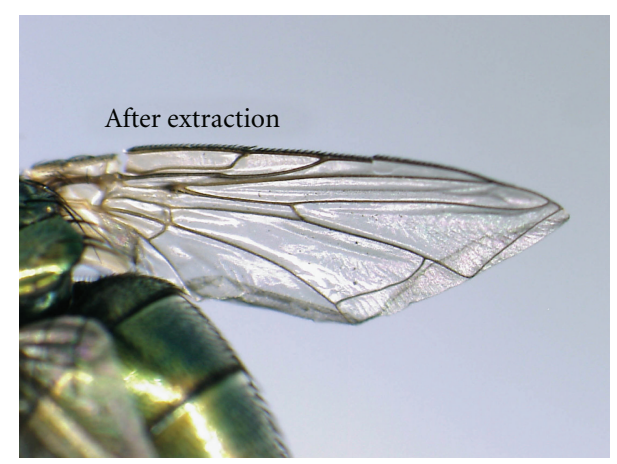

(b)

FIGURE 4: Right wing of a fly sample before and after DNA extraction shows generalized shrinkage and two disruptions in the costal vein after DNA extraction.

is 1738 base pairs including the whole mitochondrial COI gene. In the cases of shorter amplicons, both mitochondrial (629 base pairs) and nuclear (492 base pairs) markers were excellently amplified.

\subsection{Disruption of Key Features for Morphological Identifica-} tion after DNA Extraction. The overall morphologic features were excellently preserved after DNA extraction in all samples. Generally, the metallic green gloss which is typical for Luciliinae fly species became slightly dull (Figure 2). A few slight disruptions to particular morphologic features were observed. Although even small bristles were not disrupted, one of the two mid legs was lost in two samples during DNA extraction (Figure 3). Despite shrinkage to the membranous part and a few disruptions of veins, the general integrity of the wings remained intact and suitable for identification of venous branching patterns (Figure 4). Disruptions in morphological features after DNA extraction are summarized in Table 3.

\section{Discussion}

The numbers of nucleotide sequences of forensically important fly species in NCBI Genbank are rapidly increasing. However, sequence acceptance in NCBI Genbank does not guarantee the accuracy of species identification of the specimen. In the field of forensic entomology, several sequences of Calliphoridae fly species, which are quite different from other conspecific sequences or identical to heterospecific sequences, hamper accurate species identification using DNA sequences $[15,16]$. Therefore, in those cases, it is ideal for sequence submitters to share their voucher specimens for reconfirmation of morphological identification keys. According to our results using nondestructive DNA extraction, all 
of the five samples did not show any significant morphologic disruption which may affect species identification. Moreover, nondestructive DNA extraction provides a satisfactory quantity and quality of DNA for PCR amplification. This nondestructive method may be applicable to DNA extraction of rare samples as well as vouchering of regular fly samples. Although we applied traditional phenol/chloroform technique in this study, the incubated "soup" may be transferred to commercially available DNA extraction kits using spin columns.

\section{References}

[1] M. D. Dean and J. W. O. Ballard, "Factors affecting mitochondrial DNA quality from museum preserved drosophila simulans," Entomologia Experimentalis et Applicata, vol. 98, no. 3, pp. 279-283, 2001.

[2] S. H. Park, Y. Zhang, H. Piao et al., "Sequences of the Cytochrome C Oxidase Subunit I (COI) gene are suitable for species identification of Korean calliphorinae flies of forensic importance (Diptera: Calliphoridae)," Journal of Forensic Sciences, vol. 54, no. 5, pp. 1131-1134, 2009.

[3] K. Saigusa, M. Takamiya, and Y. Aoki, "Species identification of the forensically important flies in Iwate prefecture, Japan based on mitochondrial cytochrome oxidase gene subunit I (COI) sequences," Legal Medicine, vol. 7, no. 3, pp. 175-178, 2005.

[4] S. Vincent, J. M. Vian, and M. P. Carlotti, "Partial sequencing of the cytochrome oxydase b subunit gene I: a tool for the identification of European species of blow flies for postmortem interval estimation," Journal of Forensic Sciences, vol. 45, no. 4, pp. 820-823, 2000.

[5] M. L. Harvey, M. W. Mansell, M. H. Villet, and I. R. Dadour, "Molecular identification of some forensically important blowflies of southern Africa and Australia," Medical and Veterinary Entomology, vol. 17, no. 4, pp. 363-369, 2003.

[6] A. C. M. Junqueira, A. C. Lessinger, and A. M. L. AzeredoEspin, "Methods for the recovery of mitochondrial DNA sequences from museum specimens of myiasis-causing flies," Medical and Veterinary Entomology, vol. 16, no. 1, pp. 39-45, 2002.

[7] Q. L. Liu, J. F. Cai, Y. F. Chang et al., "Identification of forensically important blow fly species (Diptera: Calliphoridae) in China by mitochondrial cytochrome oxidase I gene differentiation," Insect Science, vol. 18, pp. 554-564, 2011.

[8] J. Stevens and R. Wall, "Genetic variation in populations of the blowflies Lucilia cuprina and lucilia sericata (Diptera: Calliphoridae). Random amplified polymorphic DNA analysis and mitochondrial DNA sequences," Biochemical Systematics and Ecology, vol. 25, no. 2, pp. 81-97, 1997.

[9] J. D. Wells and F. A. H. Sperling, "Molecular phylogeny of Chrysomya albiceps and C. rufifacies (Diptera: Calliphoridae)," Journal of Medical Entomology, vol. 36, no. 3, pp. 222-226, 1999.

[10] A. J. Phillips and C. Simon, "Simple, efficient, and nondestructive DNA extraction protocol for arthropods," Annals of the Entomological Society of America, vol. 88, no. 3, pp. 281-283, 1995.

[11] N. Rohland, H. Siedel, and M. Hofreiter, "Nondestructive DNA extraction method for mitochondrial DNA analyses of museum specimens," BioTechniques, vol. 36, no. 5, pp. 814-821, 2004.

[12] M. T. P. Gilbert, W. Moore, L. Melchior, and M. Worebey, "DNA extraction from dry museum beetles without conferring external morphological damage," PLoS ONE, vol. 2, no. 3, article e272, 2007.

[13] D. L. Rowley, J. A. Coddington, M. W. Gates et al., "Vouchering DNA-barcoded specimens: test of a nondestructive extraction protocol for terrestrial arthropods," Molecular Ecology Notes, vol. 7, no. 6, pp. 915-924, 2007.

[14] J. Butler, M.Forensic DNA Typing: Biology, Technology, and Genetics of STR Markers, Elsevier Academic Press, Burlington, Mass, USA, 2005.

[15] S. H. Park, Y. Zhang, H. Piao et al., "Use of Cytochrome C Oxidase Subunit I (COI) nucleotide sequences for identification of the Korean Luciliinae Fly species (Diptera: Calliphoridae) in forensic investigations," Journal of Korean Medical Science, vol. 24, no. 6, pp. 1058-1063, 2009.

[16] J. D. Wells, R. Wall, and J. R. Stevens, "Phylogenetic analysis of forensically important Lucilia flies based on cytochrome oxidase I sequence: a cautionary tale for forensic species determination," International Journal of Legal Medicine, vol. 121, no. 3, pp. 229-233, 2007. 

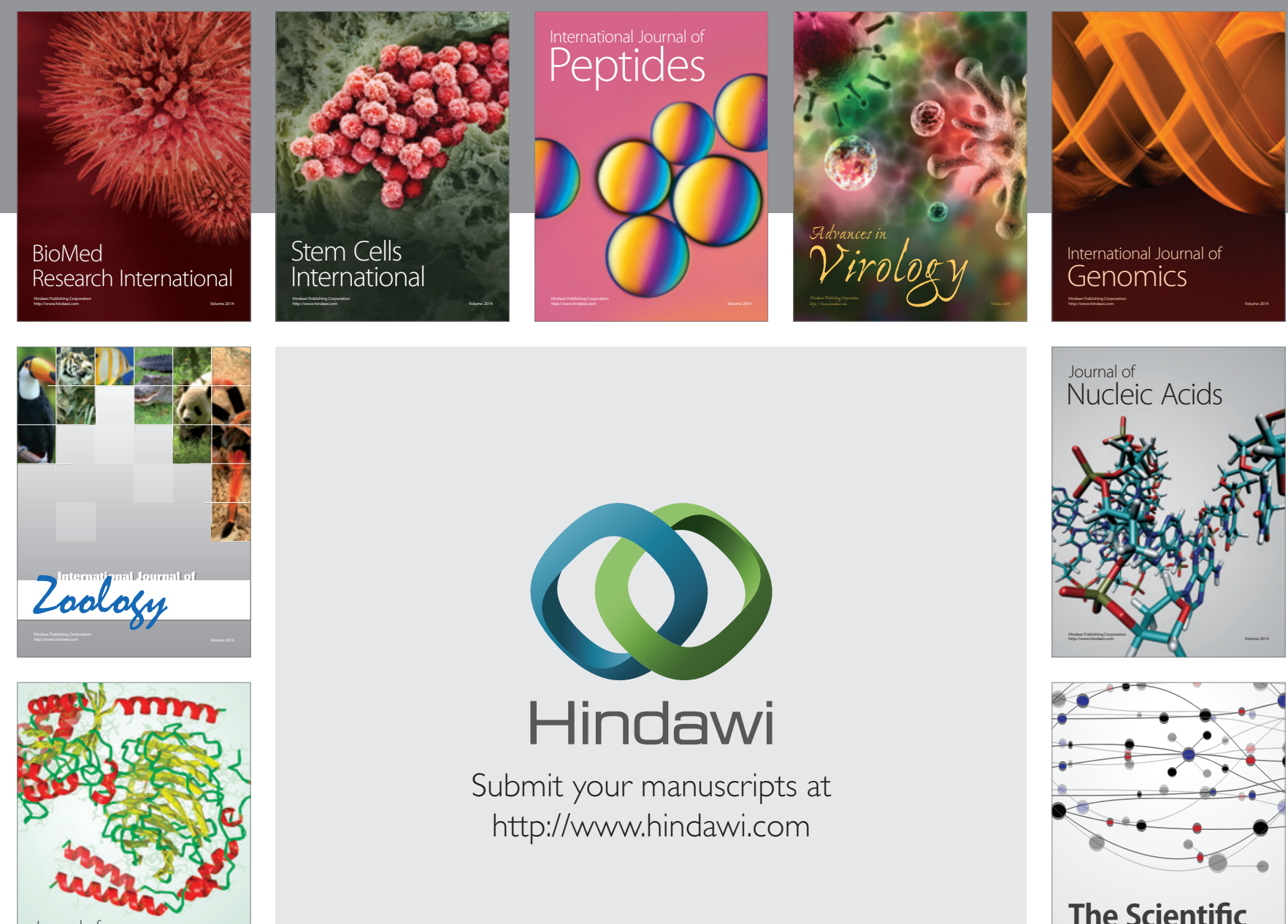

Submit your manuscripts at

http://www.hindawi.com

Journal of
Signal Transduction
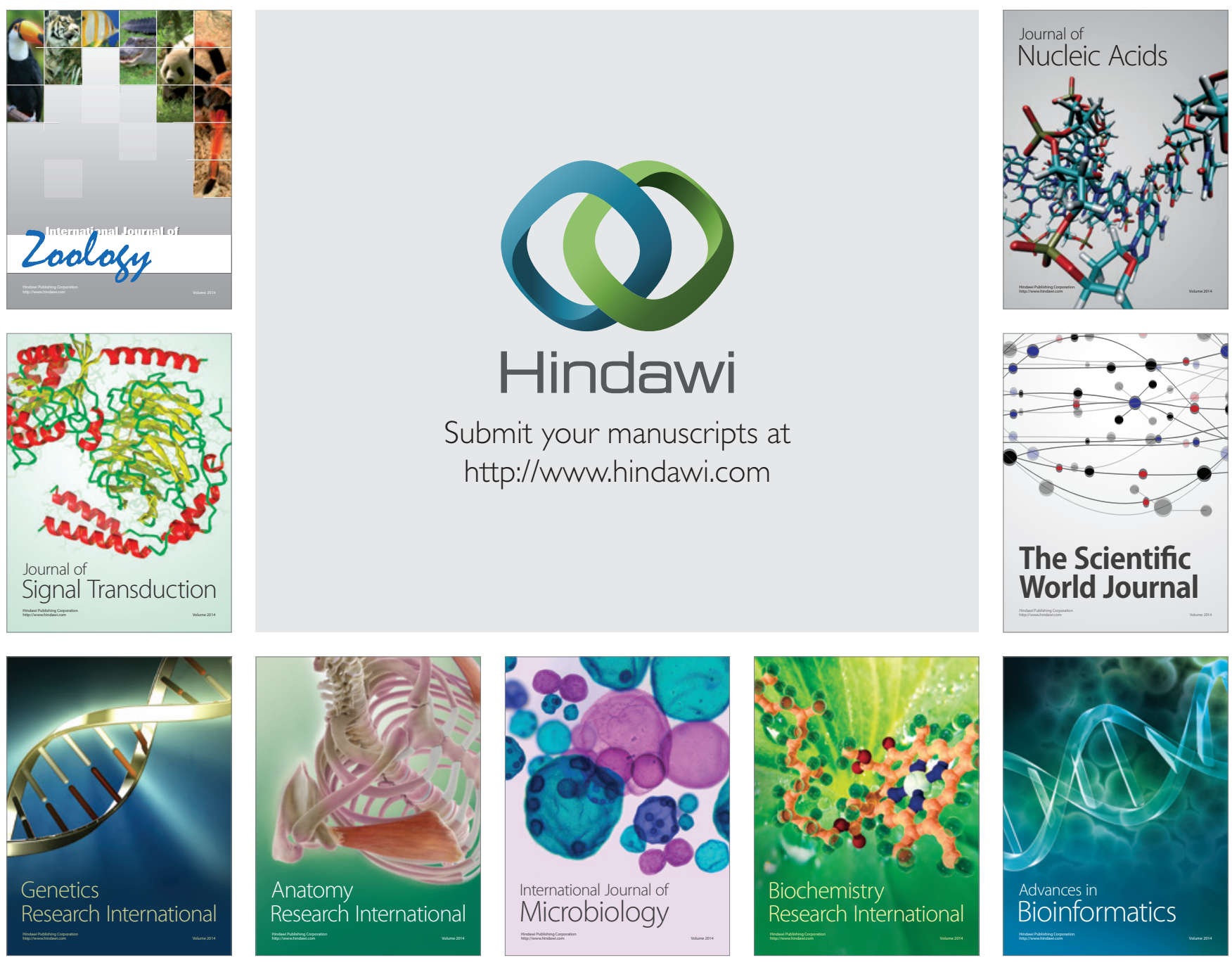

The Scientific World Journal
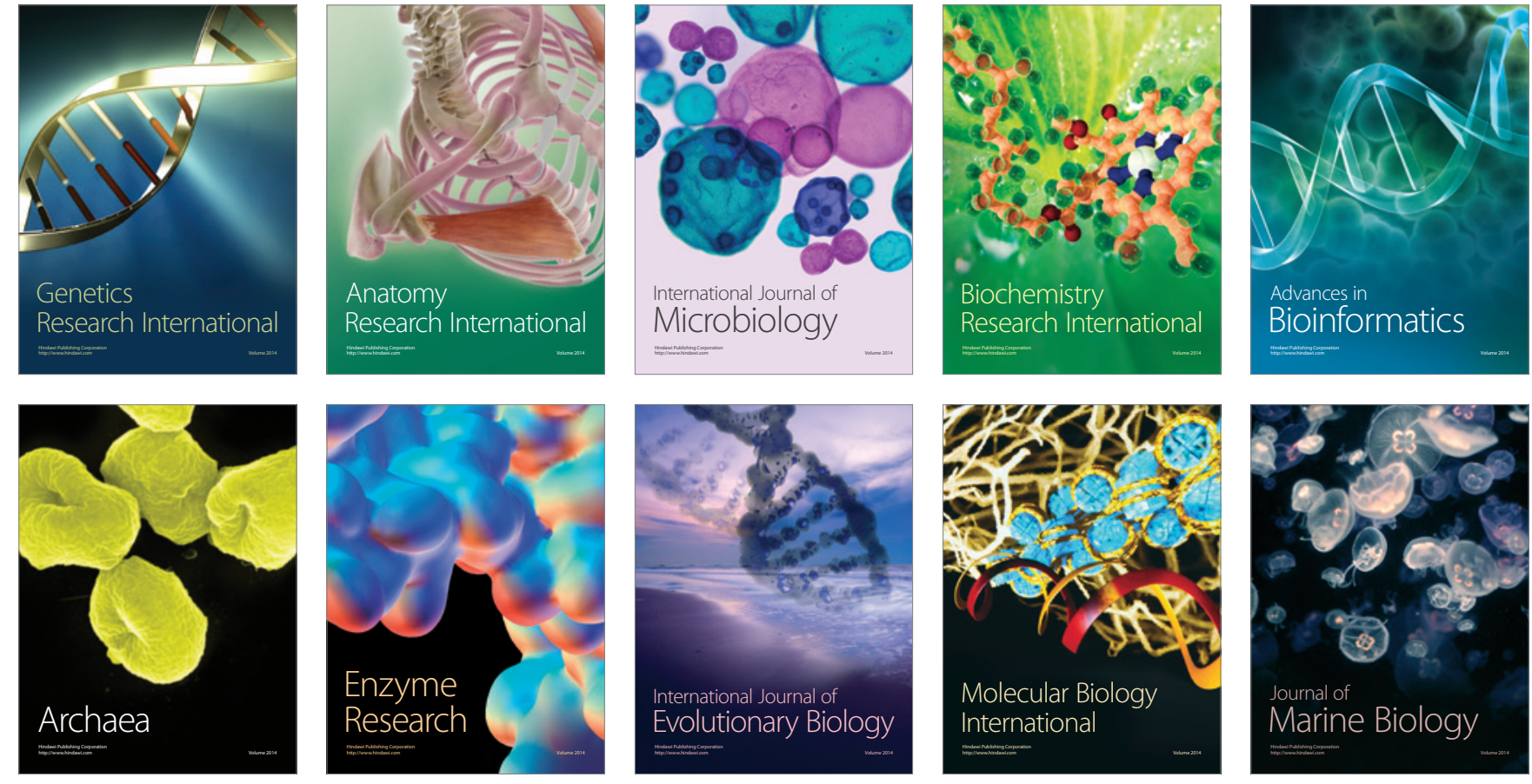